\title{
Alumina-on-Polyethylene Bearing Surfaces in Total Hip Arthroplasty
}

\author{
Jung Yup Lee and Shin-Yoon Kim*
}

Department of Orthopaedic Surgery, Graduate School of Medicine, Kyungpook National University, Daegu 700-721, Korea

\begin{abstract}
The long-term durability of polyethylene lining total hip arthroplasty (THA) mainly depends on periprosthetic osteolysis due to wear particles, especially in young active patients. In hip simulator study, reports revealed significant wear reduction of the alumina ceramic-on-polyethylene articulation of THA compared with metal-on-polyethylene bearing surfaces. However, medium to long-term clinical studies of THA using the alumina ceramic-on-polyethylene are few and the reported wear rate of this articulation is variable. We reviewed the advantages and disadvantages of ceramicon-polyethylene articulation in THA, hip simulator study and retrieval study for polyethylene wear, in vivo clinical results of THA using alumina ceramic-on-polyethylene bearing surfaces in the literature, and new trial alumina ceramic-onhighly cross linked polyethylene bearing surfaces.
\end{abstract}

Keywords: Arthroplasty, polyethylene, alumina.

\section{INTRODUCTION}

Alumina ceramic was introduced as a bearing surface in the 1971 as an alternative to the metal on-polyethylene couplings. Since then, alumina ceramic has been used in THA successfully for more than 35 years. Alumina 1970s (first generation) had a low density, a very coarse microstructure, sintered in air, and was not in compliance with specifications. Alumina 1980s (second generation) had a reduced microstructure grain size, had a laser marking, and sintered in air. Alumina 1990s (third generation, forte) had a improved mechanical strength, more reduced microstructure grain size, laser marking, proof testing of $100 \%$, and manufactured by using hot isostatic pressing. In 2000 s (fourth generation, delta), a new alumina matrix composite material with improved material properties was developed. The advantages of using alumina ceramic as a bearing surface in THA are related to its hardness, wettability, fluid film lubrication, inertness, high level of oxidation of alumina ceramic which provide resistance to scratches, and high biocompatibility $[1,2]$. These characteristics seem to make less polyethylene wear when alumina ceramic head articulates with polyethylene than metal head. In vitro hip simulator studies of alumina ceramic-on-polyethylene articulations, the wear rate of polyethylene with the alumina ceramic head was lower than that of polyethylene with metal head. Also, at equivalent particle volumes the clinically relevant alumina particles showed less toxic than cobaltchrome particles in vitro [2]. The disadvantages of alumina ceramic-on-polyethylene bearing surfaces involves the risk of alumina head fracture and the resultant difficult revision surgery [3], and metal transfer which can increase surface roughness and third body wear leading to increased polyethylene wear [4].

*Address correspondence to this author at the Department of Orthopaedic Surgery, Kyungpook National University Hospital, Samduck 2 Ga 50 JungGu, Daegu 700-721, Korea; Tel: 8253-420-5635; Fax: 8253-422-6605;

E-mail: syukim@knu.ac.kr

\section{KINDS OF CERAMIC FEMORAL HEADS}

Alumina $\left(\mathrm{Al}_{2} \mathrm{O} 3\right)$ and zirconia $(\mathrm{ZrO} 2)$ ceramic femoral heads have been widely used as more scratch-resistant bearing surfaces against PE. Alumina and zirconia heads both have high hardness and strength, which make them more difficult to scratches, and this can reduce abrasive wear. The wettability of ceramic material is another important property. Ceramics are more hydrophilic and have improved lubrication and lower friction. The fracture toughness of zirconia is reported as nearly twice that of alumina and it had higher strength, lower variability than alumina. These properties of zirconia allowed smaller heads and more neck leghth than alumina without increased risk of fracture. However, zirconia femoral heads have not performed clinically as well as alumina heads $[5,6]$. Phase transformation that can occur over a ten-year period, grain pullout, roughening, inferior wear properties, and a manufacturing-related fracture problem have resulted in the withdrawal of zirconia femoral heads in the market in 2002. Alumina ceramics showed high survivorship and low bearing wear, but concern of ceramic fracture and the resultant difficult revision surgery still persists. A new alumina matrix composite material with improved material properties was developed to address these concerns and early results showed hopeful in both ceramic-on-ceramic and ceramic-on-polyethylene articulation [7].

\section{HIP SIMULATOR STUDIES FOR WEAR OF ALU- MINA-ON-POLYETHYLENE ARTICULATION}

There are a few hip simulator studies of alumina-onpolyethylene articulations. The wear rate of polyethylene with the alumina head was lower than that of polyethylene with metal head. Saikko et al. reported the mean wear rate of cups against alumina heads was usually lower than against metallic heads in hip simulator study with saline as a lubricant, raising doubt about the clinical applicability [8]. Also, Clarke et al. reported in bovine serum based hip simulator study, alumina ceramic-on-polyethylene hip 
replacement systems offered on average a 50\% wear reduction from metal-on-polyethylene systems [9].

\section{A RETRIEVAL STUDIES FOR WEAR OF ALUMINA- ON-POLYETHYLENE ARTICULATION}

There are contradictory results for wear rate in a retrieval study. Bragdon et al. suggested that alumina ceramic-onpolyethylene wear rates are not substantially different from metal-on-polyethylene [10]. However, Kusaba and Kuroki found lower polyethylene wear for alumina compared with CoCr 32-mm heads [11].

\section{CLINICAL STUDIES FOR WEAR OF ALUMINA- ON-POLYETHYLENE ARTICULATION}

In clinical practice, there also have been confusing data about wear of alumina-on-polyethylene articulation even though mostly encouraging results. Urban et al. reported a head penetration rate of $0.034 \mathrm{~mm}$ per year with a $32 \mathrm{~mm}$ alumina head-on-gamma irradiated in air polyethylene articulation at 17 to 21 year follow-up [12]. Hernigou and Bahrami a head penetration rate of $0.071 \mathrm{~mm}$ per year with a $32 \mathrm{~mm}$ head alumina-on-polyethylene articulation at 10.8 year follow-up [13]. We previously reported a head penetration rate of $0.07 \mathrm{~mm}$ per year with a $28 \mathrm{~mm}$ head alumina-on-polyethylene articulation after a mean 9 year and 7 year follow-up measured using Livermore method, and Dorr and Wan method respectively $[14,15]$.

There are studies comparing the wear of ceramic and metallic heads. Zichner and Willert compared the radiological wear characteristics of metal and alumina ceramic femoral head articulating with polyethylene [16]. Using metallic balls using Prostasul-2, 64\% had a wear rate of less than $0.2 \mathrm{~mm}$; of those using Prostasul-10, 77\% had lower rates than $0.2 \mathrm{~mm}$. In patients where alumina balls were implanted, the displacement rate was below $0.2 \mathrm{~mm}$ per year in $95 \%$. Clarke and Gustafson indicated that alumina ceramic-on-polyethylene hip replacement systems offered on average a $50 \%$ wear reduction from metal-on-polyethylene system in laboratory and clinical data [9]. Oonishi and coworkers reported a $0.1 \mathrm{~mm}$ per year rate head penetration rate with alumina ceramic femoral heads compared with a $0.25 \mathrm{~mm}$ per year rate with stainless steel femoral heads [5]. Schuller and Marti reported a $0.03 \mathrm{~mm}$ per year rate head penetration rate with alumina ceramic femoral heads compared with a $0.10 \mathrm{~mm}$ per year rate with $\mathrm{CoCr}$ femoral heads after 9 to 11 year follow-up [17]. But variables such as age, weight, acetabular and femoral components, size of the head, manufacturer of the head, and surgical technique were not addressed in these studies.

Later, the performance of polyethylene liners articulating with alumina ceramic heads was compared with that of polyethylene liners articulating with cobalt-chrome heads in two groups of patients that were matched on age, gender, weight, acetabular and femoral components, size of the head, manufacturer of the head and surgical technique. Sychterz et al. compared the radiological wear characteristics of 81 alumina ceramic femoral heads with a well-matched group of 43 cobalt-chrome femoral heads [18]. At a mean of seven years the true rate of wear of the ceramic group was slightly greater $(0.09 \mathrm{~mm} / \mathrm{year})$ than that of the cobalt-chrome group $(0.07 \mathrm{~mm} /$ year $)$. Despite the numerous theoretical advantages of alumina ceramic over cobalt-chrome femoral heads, the wear performance in vivo of these components was similar.

Some reports showed discouraging results. Japanese authors have investigated the long-term results of cemented THA with Bioceram prostheses (Kyosera, Kyoto, Japan) and reported higher wear rate of polyethylene. The mean linear wear rates of $0.10 \mathrm{~mm} /$ year at 13 years and $0.15 \mathrm{~mm} /$ year at 13.8 years of follow-up respectively $[19,20]$.

Various wear rate of alumina-on-polyethylene bearing THA are listed at Table $\mathbf{1}[5,12-16,18,20-30]$.

There are studies comparing the wear of alumina-onalumina articulation compared with alumina ceramic-onpolyethylene recently. Hernigou et al. reported a head penetration rate of $0.07 \mathrm{~mm}$ per year alumina ceramic headon-polyethylene articulation and a head penetration rate of $13 \mathrm{um}$ per year alumina-on-alumina articulation on 28 bilateral arthroplasties in same patients at minimum 20 year follow-up [31]. Lewis et al. reported a wear rate of $0.11 \mathrm{~mm}$ per year with a $28 \mathrm{~mm}$ alumina ceramic head-onpolyethylene articulation and a head penetration rate of 0.02 um per year alumina-on-alumina articulation measured using the method of Dorr and Wan up to 10 year follow-up in a prospective randomized trial [29].

\section{CONCERN OF CERAMIC COMPLICATIONS}

There is possibility of a fracture of a ceramic head because ceramics are brittle materials [32-34]. Low fracture toughness and linear elastic behavior demonstrated by ceramic make it prone to breakage under stress. The risk of alumina head fracture is low but considerable when it occurs. Reoperation is necessary, and the outcome of the revision arthroplasty for ceramic femoral head fracture will be compromised because of retained ceramic fragments that have been shown to increase wear, to increase the development of osteolysis, and to increase the need for another revision surgery. Heavy patients and reconstructions with longer neck lengths (less contact area along taper junction) and/or high offsets appear to be at increased risk. Theoretically, improvements in morse taper design and manufacturing can minimize or eliminate this problem.

Clinically the risk of ceramic head fracture seems to be higher when articulating with rigid bearing than polyethylene one. Willmann reported on a fracture rate of $0.02 \%$ in 1.5 million heads since 1974 [35]. In a later review of the literature, he reported on a failure rate of ceramics up to $13.4 \%$ manufactured before 1990 and a failure rate of $0.004 \%$ to $0.015 \%$ for ceramics manufactured after 1990 [36]. Especially for the Biolox femoral head, Willmann saw a fracture rate of $0.026 \%$ for first generation alumina (1970s), 0.014\% for second generation alumina (1980s), and $0.004 \%$ for third generation alumina femoral heads (Biolox forte) manufactured after 1994 (1990s). Fritsch et al. analyzed over a period from 1974 to 1998, 4,341 alumina ceramic heads articulating with 2,693 alumina ceramic and 1,464 polyethylene cups [37]. They reported only one fracture of a alumina ceramic head in a alumina ceramic-onpolyethylene articulation and seven fractures in alumina-onalumina articulation whereas four fractures were related to direct trauma, two fractures were related to recurrent neck impingement and one was due to material fatigue. Heisel reported on two traumatic fractures of alumina ceramic 
Table 1. Studies of Wear Rates of Alumina-on-Polyethylene Bearing Total Hip Arthroplasty

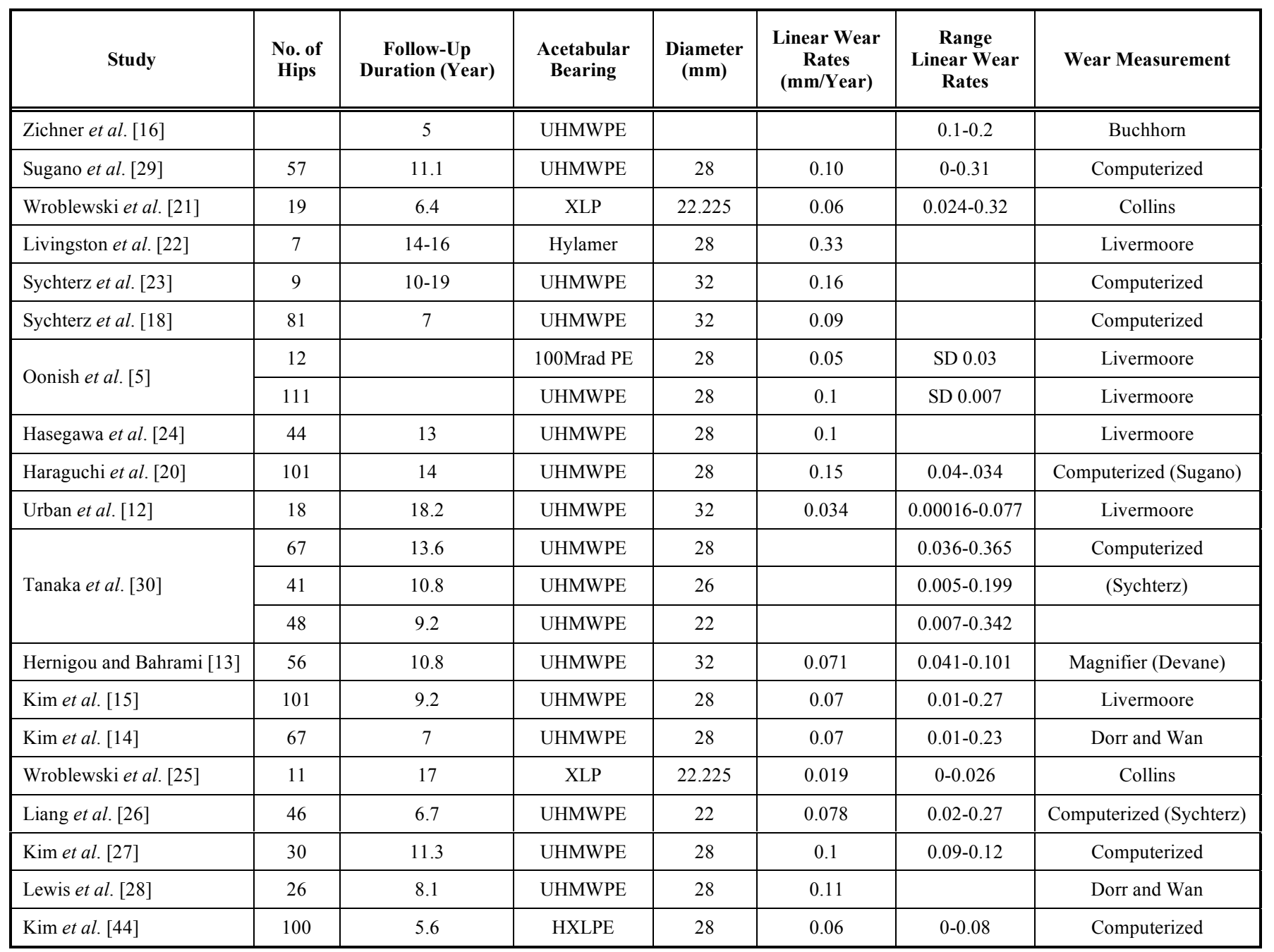

heads articulating with polyethylene in 2356 alumina ceramic hip endoprostheses [38]. Reviewing the literatures, they came to the conclusion that a fracture of the alumina ceramic head may be prevented by using a alumina ceramicon-polyethylene combination. The other concern of alumina femoral head is metal transfer which can increase surface roughness and third body wear leading to increased polyethylene wear [4].

Hasegawa et al. reported that the retrieved alumina heads (28mm Bioceram) showed smooth surfaces without scratches, but there was debris stuck to the gaps on the surfaces [19]. The authors attributed these results to uncontrolled factors, such as third-body wear and levels of activity. This result is contrary to the report of Wang and Essner [39]. They found that ceramic heads were effective in reducing polyethylene wear because of the inability of thirdbody particles to adhere to their surfaces rather than due to their resistance to scratching.

Squeaking is another problem of alumina-on-alumina bearing surface. This phenomenon had not been reported in alumina-on-polyethylene articulation and is unique in ceramic-on-ceramic articulation.

\section{WEAR FOR ALUMINA-ON-HIGHLY CROSS-LINKED POLYETHYLENE BEARING SURFACE}

The successful long-term clinical experience with ultrahigh molecular weight polyethylene as a bearing surface has prompted the development of more wear-resistant highly cross-linked polyethylene [26]. The principle is to enhance chain cross-linkage between crystals by radiation and avoid free radical oxidation by secondary heat treatment. This change in structure should significantly improve wear resistance and reduce polyethylene wear debris release and it have shown excellent medium-term clinical results $[26,40]$. The manufacturing processes of the currently available products differ in dose and type of irradiation (gamma radiation or electron beam), thermal stabilization (remelting or annealing), machining, and final sterilization. This treatment significantly improves wear, and alters the mechanical properties of polyethylene, proportionally to the radiation dose. Even so, in vitro hip simulator studies show a very low wear rate unaffected by the use of large head diameters [41].

Wroblewski et al. confirmed hip simulator results for the wear characteristics, that alumina ceramic femoral heads penetrate the highly chemically cross-linked polyethylene cups at only about half the rate of otherwise comparable 
metal heads [21]. Subsequently, he reported a head penetration rate of $0.019 \mathrm{~mm}$ per year with a $22.225 \mathrm{~mm}$ alumina ceramic head-on-chemically cross-linked polyethylene articulation at 17 year follow-up [26]. Oonishi et al. reported a head penetration rate of $0.05 \mathrm{~mm}$ per year with a $28 \mathrm{~mm}$ alumina ceramic head-on-100Mrad irradiated crosslinked polyethylene articulation at 14-16 year follow-up [26]. There is only one clinical trial using alumina ceramicon-currently available highly cross-linked polyethylene bearing surface in the literature. Kim et al. reported the mean annual penetration of $0.06 \mathrm{~mm}$ in cementless THA with $28 \mathrm{~mm}$ alumina ceramic (forte)-on-highly cross-linked polyethylene (Marathon, Depuy, Warsaw, Indiana, USA) bearing surface after 5.6 years follow-up in the 100 patients younger than 50 years of age. Callaghan continues to use alumina ceramic-on-highly cross-linked polyethylene bearing surfaces in the patients at higher risk for wear in THA [42].

These new polyethylenes, on the other hand, show reduced resistance to cracking (lower plasticity). Holley et al. studied an impingement model on a hip simulator and found greater wear under these condition [43]. Overall, there is less tolerance than with conventional polyethylene, and the disadvantages resemble those of hard-on-hard couples. But most reports support that clinical findings confirm the good trend.

\section{CONCLUSION}

Although there are different wear rate in hip simulator studies and retrieval studies about alumina ceramic-onpolyethylene articulation, the clinical wear performances of these articulations in THA showed significant reduction of polyethylene wear compared with meta-on-polyethylene articulation. Mostly, wear rate of alumina ceramic-onpolyethylene articulation showed less than "so called osteolysis threshold" of $0.10 \mathrm{~mm}$ per year. Also, incidence of alumina ceramic head fracture was rare compared with ceramic-on-ceramic bearing surfaces. Squeaking in aluminaon-alumina bearing surface had not been reported in alumina ceramic-on-polyethylene articulation.

Competition between various articulations in order to reduce wear and to improve the longevity of THA will be continued through next decades. In that, alumina ceramic-onpolyethylene including recently developed highly crosslinked polyethylene articulation would be remained as a good option for THA especially young and active patients. Further manufacturing and material development, improvements in the processing of ceramic as well as advances in engineering of head-neck articulations and liner design will lead to more favorable clinical results and decrease in the incidence of ceramic fracture and dislocation. In future, it is necessary to perform prospective randomized comparative studies to compare various bearing surfaces in patients matched in age, sex, diagnosis, body mass index, kinds of polyethylene and ceramic head according to manufactures, head diameter, follow-up period, and measuring method for wear.

\section{REFERENCES}

[1] Clarke IC. Role of ceramic implants. Design and clinical success with total hip prosthetic ceramic-to-ceramic bearings. Clin Orthop Relat Res 1992; 282: 19-30.
[2] Germain MA, Hatton A, Williams S, et al. Comparison of the cytotoxicity of clinically relevant cobalt-chromium and alumina ceramic wear particles in vitro. Biomaterials 2003; 24(3): 469-79.

[3] Heisel C, Silva M, Schmalzried TP. Bearing surface options for total hip replacement in young patients. Instr Course Lect 2004; 53: 49-65.

[4] Della Valle AG, Doty S, Gradl G, Labissiere A, Nestor BJ. Wear of a highly cross-linked polyethylene liner associated with metallic deposition on a ceramic femoral head. J Arthroplasty 2004; 19(4): 532-6.

[5] Oonishi H, Wakitani S, Murata N, et al. Clinical experience with ceramics in total hip replacement. Clin Orthop Relat Res 2000; 379: 77-84.

[6] Santos EM, Vohra S, Catledge SA, McClenny MD, Lemons J, Moore KD. Examination of surface and material properties of explanted zirconia femoral heads. J Arthroplasty 2004; 19(7 Suppl 2): $30-4$.

[7] Hamilton WG, McAuley JP, Dennis DA, Murphy JA, Blumenfeld TJ, Politi J. THA with delta ceramic on ceramic: results of a multicenter investigational device exemption trial. Clin Orthop Relat Res 2009; 468: 358-66.

[8] Saikko V, Ahlroos T, Calonius O, Keranen J. Wear simulation of total hip prostheses with polyethylene against $\mathrm{CoCr}$, alumina and diamond-like carbon. Biomaterials 2001; 22(12): 1507-14.

[9] Clarke IC, Gustafson A. Clinical and hip simulator comparisons of ceramic-on-polyethylene and metal-on-polyethylene wear. Clin Orthop Relat Res 2000; 379: 34-40.

[10] Bragdon CR, Jasty M, Kawate K, et al. Wear of retrieved cemented polyethylene acetabula with alumina femoral heads. J Arthroplasty 1997; 12(2): 119-25.

[11] Kusaba A, Kuroki Y, Kondo S, et al. Frictional torque and wear of retrieved hip prostheses: A comparison between alumina/PE and Co-Cr/PE prostheses. J Long Term Eff Med Implants 2002; 12(1): $53-62$.

[12] Urban JA, Garvin KL, Boese CK, et al. Ceramic-on-polyethylene bearing surfaces in total hip arthroplasty. Seventeen to twenty-oneyear results. J Bone Joint Surg Am 2001; 83-A(11): 1688-94.

[13] Hernigou P, Bahrami T. Zirconia and alumina ceramics in comparison with stainless-steel heads. Polyethylene wear after a minimum ten-year follow-up. J Bone Joint Surg Br 2003; 85(4): 504-9.

[14] Kim SY, Kim DH, Oh CW, Kim PT, Ihn JC. Total hip arthroplasty with the use of nonmodular cementless acetabular component. J Arthroplasty 2005; 20(5): 632-8.

[15] Kim YG, Kim SY, Kim SJ, Park BC, Kim PT, Ihn JC. The use of cementless expansion acetabular component and an aluminapolyethylene bearing in total hip arthroplasty for osteonecrosis. J Bone Joint Surg Br 2005; 87(6): 776-80.

[16] Zichner LP, Willert HG. Comparison of alumina-polyethylene and metal-polyethylene in clinical trials. Clin Orthop Relat Res 1992; 282: 86-94

[17] Schuller HM, Marti RK. Ten-year socket wear in 66 hip arthroplasties. Ceramic versus metal heads. Acta Orthop Scand 1990; 61(3): 240-3.

[18] Sychterz CJ, Engh CA Jr, Young AM, Hopper RH, Jr., Engh CA. Comparison of in vivo wear between polyethylene liners articulating with ceramic and cobalt-chrome femoral heads. J Bone Joint Surg Br 2000; 82(7): 948-51.

[19] Hasegawa M, Sudo A, Hirata H, Uchida A. Ceramic acetabular liner fracture in total hip arthroplasty with a ceramic sandwich cup. J Arthroplasty 2003; 18(5): 658-61.

[20] Haraguchi K, Sugano N, Nishii T, Sakai T, Yoshikawa H, Ohzono $\mathrm{K}$. Influence of polyethylene and femoral head surface quality on wear: a retrieval study. Int Orthop 2001; 25(1): 29-34.

[21] Wroblewski BM, Siney PD, Dowson D, Collins SN. Prospective clinical and joint simulator studies of a new total hip arthroplasty using alumina ceramic heads and cross-linked polyethylene cups. J Bone Joint Surg Br 1996; 78(2): 280-5.

[22] Livingston BJ, Chmell MJ, Spector M, Poss R. Complications of total hip arthroplasty associated with the use of an acetabular component with a Hylamer liner. J Bone Joint Surg Am 1997; 79(10): 1529-38.

[23] Sychterz CJ, Engh CA Jr, Shah N, Engh CA Sr. Radiographic evaluation of penetration by the femoral head into the polyethylene liner over time. J Bone Joint Surg Am 1997; 79(7): 1040-6. 
[24] Hasegawa M, Ohashi T, Tani T. Poor outcome of 44 cemented total hip arthroplasties with alumina ceramic heads: Clinical evaluation and retrieval analysis after 10-16 years. Acta Orthop Scand 2001; 72(5): 449-56.

[25] Wroblewski BM, Siney PD, Fleming PA. Low-friction arthroplasty of the hip using alumina ceramic and cross-linked polyethylene. A 17-year follow-up report. J Bone Joint Surg Br 2005; 87(9): 12201.

[26] Liang B, Kawanabe K, Ise K, Iida H, Nakamura T. Polyethylene wear against alumina and zirconia heads in cemented total hip arthroplasty. J Arthroplasty 2007; 22(2): 251-7.

[27] Kim YH, Kim JS. Tribological and material analyses of retrieved alumina and zirconia ceramic heads correlated with polyethylene wear after total hip replacement. J Bone Joint Surg Br 2008; 90(6): 731-7.

[28] Lewis PM, Al-Belooshi A, Olsen M, Schemitch EH, Waddell JP. Prospective randomized trial comparing alumina ceramic-onceramic with ceramic-on-conventional polyethylene bearings in total hip arthroplasty. J Arthroplasty 2009; [Epub ahead of print]

[29] Sugano N, Nishii T, Nakata K, Masuhara K, Takaoka K. Polyethylene sockets and alumina ceramic heads in cemented total hip arthroplasty. A ten-year study. J Bone Joint Surg Br 1995; 77(4): 548-56.

[30] Tanaka K, Tamura J, Kawanabe K, Shimizu M, Nakamura T. Effect of alumina femoral heads on polyethylene wear in cemented total hip arthroplasty. Old versus current alumina. J Bone Joint Surg Br 2003; 85(5): 655-60.

[31] Hernigou P, Zilber S, Filippini P, Poignard A. Ceramic-ceramic bearing decreases osteolysis: A 20-year study versus ceramicpolyethylene on the contralateral hip. Clin Orthop Relat Res 2009; 467(9): 2274-80.

[32] Callaway GH, Flynn W, Ranawat CS, Sculco TP. Fracture of the femoral head after ceramic-on-polyethylene total hip arthroplasty. J Arthroplasty 1995; 10(6): 855-9.
[33] Hummer CD, 3rd, Rothman RH, Hozack WJ. Catastrophic failure of modular zirconia-ceramic femoral head components after total hip arthroplasty. J Arthroplasty 1995; 10(6): 848-50.

[34] Michaud RJ, Rashad SY. Spontaneous fracture of the ceramic ball in a ceramic-polyethylene total hip arthroplasty. J Arthroplasty 1995; 10(6): 863-7.

[35] Willmann G. Ceramics for total hip replacement--what a surgeon should know. Orthopedics 1998; 21(2): 173-7.

[36] Willmann G. Ceramic femoral head retrieval data. Clin Orthop Relat Res 2000; 379: 22-8.

[37] Fritsch EW, Gleitz M. Ceramic femoral head fractures in total hip arthroplasty. Clin Orthop Relat Res 1996; 328: 129-36.

[38] Heisel J, Schmitt E. Implant fractures in ceramic hip endoprostheses. Z Orthop Ihre Grenzgeb 1987; 125(5): 480-90.

[39] Wang A, Essner A, Stark C, Dumbleton JH. Comparison of the size and morphology of UHMWPE wear debris produced by a hip joint simulator under serum and water lubricated conditions. Biomaterials 1996; 17(9): 865-71.

[40] Digas G, Karrholm J, Thanner J, Malchau H, Herberts P. Highly cross-linked polyethylene in cemented THA: Randomized study of 61 hips. Clin Orthop Relat Res 2003; 417: 126-38.

[41] Kelly NH, Rajadhyaksha AD, Wright TM, Maher SA, Westrich $\mathrm{GH}$. High stresses conditions do not increase wear of thin highly crosslinked UHMWPE. Clin Orthop Relat Res 2010; 468: 418-23.

[42] Callaghan JJ, Liu SS. Ceramic on crosslinked polyethylene in total hip replacement: any better than metal on crosslinked polyethylene? Iowa Orthop J 2009; 29: 1-4.

[43] Holley KG, Furman BD, Babalola OM, Lipman JD, Padgett DE, Wright TM. Impingement of acetabular cups in a hip simulator: comparison of highly cross-linked and conventional polyethylene. J Arthroplasty 2005; 20(7Suppl 3): 77-86.

[44] Kim YH, Kim JS, Choi YW, Kwon OR. Intermediate results of simultaneous alumina-on-alumina bearing and alumina-on-highly cross-linked polyethylene bearing total hip arthroplasties. J Arthroplasty 2009; 24(6): 885-91.

(C) Lee and Kim; Licensee Bentham Open.

This is an open access article licensed under the terms of the Creative Commons Attribution Non-Commercial License (http://creativecommons.org/licenses/by$\mathrm{nc} / 3.0 /$ ) which permits unrestricted, non-commercial use, distribution and reproduction in any medium, provided the work is properly cited. 